\title{
Pareto on the History Of Economic Thought as an Aspect of Experimental Economics
}

\author{
by \\ Michael McLure* \\ University of Western Australia \\ Economics Program \\ Crawley, WA 6009, \\ AUSTRALIA
}

\begin{abstract}
The reasons for studying the history of economic thought are diverse. The extreme range of reasons include suggestions that research in this field is: a way of passing time on an intellectual curiosity; an investment in human capital which contributes to a more profound understanding of modern economic theory; an activity of historical interest only, totally devoid of concern with the purely scientific merits of theories; or a subject for sociologists intent on understanding the culture of science and how this has influenced the evolution of scientific knowledge. Interestingly, Pareto had a well developed idea of the scientific reasons for undertaking histories of economic thought, which he saw as an aspect of "experimental economics". This paper investigates how, and why, Pareto incorporated the history of economic thought as a central element of experimental economics. His approach to the history of economics is shown to be historical, albeit in a limited sense, and non-historical, in the sense that it provided data for the development of experimental hypotheses and theory pertaining to the sociological part of the economic phenomenon.
\end{abstract}

Key Words: Exegesis, Experimental Economics, History of Economic Thought, Pareto.

JEL Codes: B13, B31

\section{1) Introduction}

The recent $A$ Companion to the History of Economic Thought (Samuels, Biddle and Davis 2003) is a very useful resource for historians of economics, mainly because the second of its two parts is devoted entirely to historiography. ${ }^{1}$ It critically considers Whig history, rational reconstruction, historical reconstruction, the sociology of knowledge, textual exegesis, biography and a range of other topics in historiography. A priori, scholars familiar with Pareto's work may have expected some discussion of his views on historiography to be included in this part of the book. In addition to being a major economic theorist, his enduring contribution to sociology primarily concerns the sociology of knowledge and he wrote, in some detail, on the purpose of

\footnotetext{
${ }^{*}<$ Michael.McLure@uwa.edu.au>. This paper was also presented at the $2^{\text {nd }}$ conference of the Associazione Italiana per la Storia del'Economia Politica (Università degli Studi di Siena, 4-5 June 2005). The author would like to thank Vincenzo Savini and Rocco Loiaccono for preparing the translations of Italian text cited in this paper.

${ }^{1}$ See McLure (2004a) for a review of this interesting book.
} 
histories of economics and the role of textual analysis when undertaking such studies. However, the part of $A$ Companion to the History of Economic Thought that deals with historiography completely ignores Pareto on this subject. ${ }^{2}$

However, these comments are not a criticism of $A$ Companion to the History of Economic Thought. Rather, they are intended to highlight a fact: Pareto has had no influence on the development of research methods in the history of economics, at least not in the English speaking world. In this regard, the author has been unable to identify any work on historiography that examines Pareto's rather unique and well considered views on the relevance and methods of the history of economics. In some ways this is perplexing, because his work on textual analysis in the history of economics appears sophisticated, even by today's standards. Furthermore, intellectual historians have failed to investigate Pareto's views on the relevance of the history of economics to the development of theory concerning economic phenomena.

The purpose of this paper is to review and evaluate Pareto's position on treating the history of economics as an aspect of experimental economics. Emphasis is given to "Economia Sperimentale" (Pareto [1918] 1980), as this is the Giornale degli Economisti article in which Pareto most clearly and unequivocally reflected on the relevance of the history of economics, and to the aspects of his Trattato di Sociologia Sociale (Pareto [1916] 1935) that provide the interpretive context for much of "Economia Sperimentale", especially the sociological basis for textual analysis in the history of economics.

Section 2 commences by considering what Pareto meant by 'experimental economics' and, in this experimental context, highlighting his distinction between theories pertaining to the economic part of the economic phenomenon and theories pertaining to the sociological part of the economic phenomenon. Section 3 considers the manner in which Pareto treated the history of economics as experimental economics. It is suggested that the objective of his history of economics is not purely historical; rather, it is intended as an instrument for developing theory of the sociological part of the economic phenomenon. However, the means of realising this objective are historical. Section 4 examines the implications of Pareto's approach: it contrasts Stigler's principle of scientific exegesis with Pareto's use of textual analysis in the history of economics and considers the discipline that scholars should come from to undertake Paretian studies in the history of economics. It also considers whether Pareto's approach has value to modern historians of economic thought. The paper concludes, in Section 5, with the finding that historians of economics should find Pareto's work on the history of economics relevant in the case of: (i) purely historical studies of Pareto's experimental economics, because he treated the history of economics as a core aspect of experimental economics; (ii) purely historical studies of historiography, to consider why Pareto's approach to the history of economics did not prove influential while his experimental economics did; and (iii) contemporary studies of historiography, because it has the potential to complement modern research methods for the history of economics.

\footnotetext{
${ }^{2}$ The only reference in this part of the book is a casual illustrative comment on hypothetical deduction: "Pareto's mathematically formulated (log-normal) Law of Wages has stood up in repeated Crucial Experiments, but it was derived inductively and lacks any deductive core.” (Perlman 2003, p. 648).
} 


\section{2) Experimental Economics}

Pareto's system of analysis is predicated on three major ontological elements. First, he recognised that all observed social 'facts' are influenced, to varying degrees, by subjective factors which 'deform' representations of the objective phenomenon. ${ }^{3}$ Second, he suggested that subjective influences need not totally dominate scientific observation of social facts in experimental science because subjective influences on observation can be progressively reduced (not eliminated) in the classes of theory that are capable of scientific progress. The accumulation of scientific knowledge enables observers to progressively reduce the influence of subjective factors on observations of social conduct, enabling observation to bring social scientists closer to the objective phenomenon. Of course, he recognised that non-experimental sciences may not progress: it is only experimental science that Pareto linked to increased knowledge. Third, and most important for his views on the history of economics, he contended that the objective form of a phenomenon can be directly observed (albeit imperfectly) and the subjective form can be indirectly observed as residual 'sentiment' evident from textual analysis (once pure reason has been stripped away from text).

Importantly, Pareto did not just recognise the objective form and the subjective form of phenomena, he also emphasised interaction between the objective and subjective forms. This was the catalyst for Pareto treating the social phenomena as a dichotomy: one which required treatment using two distinct sets of analytical methods. One set of analytical methods was adopted for circumstances where each individual's subjective intent is independent of objective events and acts as a constant (invariable) force on human action in like objective circumstances. This set of analytical methods provides for highly deterministic closed system analysis predicated on logical action. Another set of analytical methods was required when each individual's subjective intent is interdependent with objective events, resulting in subjective intent acting as a variable force on human action in otherwise like objective circumstances. This set of analytical methods is predicated on non-logical action and only provides for a low degree of determinism and relatively open ended system analysis.

Pareto regarded the economic phenomenon as covering both sides of this dichotomy, and for the economic phenomenon to be investigated with analytical instruments appropriate for each side of the dichotomy. The primary issue Pareto faced when studying economic phenomena concerned the first part of the dichotomy: how to undertake experimental investigation of economic conduct when human action is influenced by subjective elements in a 'constant' manner under like objective circumstances. This may be considered the 'economic part' of the economic phenomenon, and it is the subject of pure economic theory. The secondary issue in Pareto's study of economic phenomena was how to undertake experimental investigation of conduct when human action is influenced by subjective elements in a variable manner in like objective circumstances. This may be called the 'sociological part' of the economic phenomenon, which Pareto studied with reference to the history of economics.

\footnotetext{
${ }^{3}$ Pareto ([1901-02] 1974, pp.137-38).
} 


\section{The 'Economic Part' of the Economic Phenomenon}

Pareto's pure economic equilibrium addresses the economic part of the study of the economic phenomenon. In this context, experimentalism is presented as the cornerstone of economic study. Importantly, experimentalism to Pareto was not just about observation, as it also relied on abstractions to identify general uniformities:

"we are still perfectly within the experimental field, as long as we never forget that these abstractions were created by us, that they do not dominate the facts but are themselves dominated by the facts, and that the results to which they will lead us do not conform to experience but within certain limits, and that, in order to have a concept, however distant and rough, of these limits, it is necessary to define either rigorously, or approximately, or, at worst, roughly, how these abstractions of the facts are obtained." (Pareto [1918] 1980, p. 725)

To underline his conviction that abstractions must be dominated by facts and conform with experience, "Economia Sperimentale" devotes considerable attention to non-experimental approaches to value theory. After confessing his 'ignorance' of the notion we call value, and armed only with an understanding of the experimental method, Pareto sought enlightenment from the works of Paul Leroy-Beaulieu (1896), John Bates Clark (1907) and Camillo Supino (1904). With a level of sarcasm that was not a-typical, he could find no experimental meaning of this notion in the work of these authors, only propositions in which abstractions dominate facts. ${ }^{4}$ When Pareto introduced his own abstraction, ophelimity, it was subordinate to facts. The experimental character of pure theory does not depend on whether an ordinal or cardinal approach to value is utilized, rather, it simply requires "... a mathematical function of experimental data" (Pareto [1918] 1980, p. 719). Mathematical economics does not loose its experimental character:

"if the abstraction of ophelimity were only put forward as a hypothesis, with the obligation to verify experimentally the results the hypothesis leads to. But mathematical Economics loses its character as a logicoexperimental science if it allows ophelimity to exist independently of the facts of which an explanation is sought, and if it wishes to assume the logical consequences of a hypothesis as demonstrations." (Pareto [1918] 1980, p. 728)

Critically, Pareto's notion of experimental economics does not end here. In fact, the fundamental importance of experimental observation in Pareto's system is largely missed if one does not relate experimental economics back to his basic behavioural dichotomy. The primary purpose of experimental economics is to confirm whether an economic phenomenon is dominated by its 'economic part' (in which case subjective intent acts as a constant force on human action in like objective circumstances) or whether it is dominated by its 'sociological part' (in which case subjective intent is dependent on objective events and acts as a variable force on human action in like objective circumstances). Phenomena that fall into the first part are amenable to theoretical representation based on deductive reasoning that

\footnotetext{
${ }^{4}$ Pareto's views on "the cause of value" are examined in McLure (1999).
} 
commences from a hypothetical postulate, such as the postulate of ophelimity maximizing action. Phenomena that fall into the second part are not. Instead, they are treated by deduction based on uniformities first established through textual analysis.

The experimental character of the 'economic part' of Pareto's study of the economic phenomenon has been well considered recently in Marchionatti and Gambino (1997), Marchionatti (1999) and Bruni (2002). However, the importance of the experimental character of economics for the sociological part of Pareto's study of the economic phenomenon has not received due consideration. The two parts must be considered together before Pareto's notion of experimental economics can be fully appreciated. That is, experimentalism provides the basis for determining whether the economic or sociological parts prevail in economic problems:

"there is almost no concrete problem that is exclusively economic, and not economic and sociological at the same time. In fact, very often the sociological part prevails over the economic part; examples of this are: the problem of free trade, or tariff protection; many monetary problems; almost all taxation problems; and other similar problems. ... one does not leave the experimental field if one studies the economic and sociological parts separately." (Pareto [1918] 1980 , p. 733).

\section{3) The History of Economics as 'Experimental Economics'}

The important feature of Pareto's sociology is that economic theories are observable facts, and the history of economics provides for the analysis of 'facts' from which hypothetical propositions can be developed in relation to the 'sociological part' of the economic phenomenon. That is, the history of economics provides the basis for developing theories pertaining to the sociological part of the economic phenomenon for which axiomatic modelling produces poor (unacceptable) approximations:

“... theories are facts. This remark is very true, and the history of those facts is the foundation of a theory about them, that is, a theory about theories." (Pareto [1918] 1980 , p. 742).

To appreciate the importance of Pareto's theory of theories to experimental economics, it is first necessary to consider the distinction between the intrinsic and extrinsic elements of theory, as outlined in his Sociologia. The intrinsic aspect concerns the soundness of theory in terms of its relationship to facts and the extrinsic ${ }^{5}$ aspect concerns the relationship between a theory and society collectively without regard to the theory's intrinsic scientific merit. Intrinsic merit is considered with reference to the closeness of the relationship to theory and fact pertaining to the primary phenomenon under investigation, and the extrinsic considers the merits or demerits of action advocated by theories for various members of society (those who advance a theory or those who adopt a theory) or for society more generally.

Pareto's theory of theories, which he referred to as derivations, suggests that theories derive from subjective sentiments, which are linked to the extrinsic aspects.

\footnotetext{
${ }^{5}$ Bruni (2002, p.40-41) dates Pareto's interest in the extrinsic aspect of science to at least 1898.
} 
Derivations have been discussed thoroughly and extensively elsewhere (Parsons 1937, Finer 1966, Tarascio 1968, de Pietri-Tonelli and Bousquet 1994), so for the purpose of this study it is adequate to simply note that they combine sentiment and reason in a non-experimental manner. Importantly, the use of textual devices to persuade can be systematically analysed. Theories may utilise assertion, ranging from theoretical hypothesis to blunt statement of apparently self evident truths, make reference to the authority of authors (distinguished scholars, schools or traditions), make reference to sentiment and metaphysics (vague social welfare notions associating benefit to those who advance an idea to the benefit of the collective) or utilise analogies. If these devices are adopted in experimental theory, they are being used to support the development of intrinsic science by illustrating theory or persuade others of its scientific merit. However, the main use of such devices, which was of most interest to Pareto, was non-experimental: to persuade and influence others by exaggerating the extrinsic benefits of proposed action (policy).

Pareto's textual exegesis of the history of economic theories revolves around the relationship between both the intrinsic and the extrinsic: "Both methods, if used exclusively, are equally incomplete." (Pareto [1916] 1935, pp.503-04). When the intrinsic aspects of theory dominate, science is experimental. Analysis of the extrinsic was designed to provide insight into human action when the individual's subjective intent is interdependent with objective events, with the extrinsic aspects of social doctrines and theories significant sources variation in subjective forces through 'persuasion' and preference modification.

One important implication of the intrinsic-extrinsic distinction for the history of economics is the necessity of considering whether progress in economic theory is 'asymptotic', in which case scientific knowledge is cumulative but imperfect, or not asymptotic, in which case knowledge is neither cumulative nor perfect. It is asymptotic when the intrinsic aspect of theory continues to grow, permitting intellectual historians to speak of progress in particular classes of economic theory. If it is not asymptotic, the intrinsic aspects merely fluctuate as new extrinsic elements are introduced in response to extrinsic considerations, in which case historians cannot speak of progress in the remaining classes of economic theory.

Interestingly, in History of Economic Analysis, Joseph Schumpeter (1954) faced similar interpretive issues, and his classification of economics texts bear some relation to Pareto's generic intrinsic-extrinsic distinction. Schumpeter classed economics texts in term of whether they dealt with: systems of political economy; economic thought; or economic analysis. The history of systems of political economy was characterised as dealing with opinions and desires about the economic system and the history of economic thought was characterised as dealing with ideas about public policy and economics. These two classes of text may be considered broad examples of what Pareto associated with the extrinsic elements of theory. Schumpeter's notion of the history of economic analysis, which is the main aspect of his interest in intellectual history, is concerned with scientific progress and is closely related to Pareto's general notion of intrinsic aspects of science. However, the similarity must not be overstated: while both masters stressed the sociology of knowledge, to Pareto this field was the primarily consideration for the extrinsic aspects of science, whereas to Schumpeter 'vision' and ideology were treated as important motivating factors in scientific progress. The similarity concerns their understanding of the interpretive 
problem, but their objectives for the history of economics were different. As a consequence, their solutions to this interpretive problem were diverse, and the focus of their historical research, were quite different.

\section{History of Economics - The 'Economic Part'}

In regard to analysis of theory pertaining to the economic part of the economic phenomenon, namely the theory of economic equilibrium for the analysis of exchange and production, Pareto acknowledged the asymptotic or cumulative view of scientific knowledge. This is because experimental observation has confirmed that modelling equilibrium on the assumption that subjective intent is a constant influence in given objective circumstances provides an acceptable first approximation to reality. In such circumstances, the history of economics is an end in itself and its progress can be considered using essentially logical criteria. In modern terms, rational criteria would be used to historically review progress in a discipline. The rational criteria are acknowledged as imperfect (the current state of knowledge in a particular place and time), but they allow an approximate indication of progress.

In the case of economic phenomena dominated by the economic aspect, such as for the theories of exchange and production, the result of Paretian history of economics is essentially Whig history. This is because such theories are dominated by their 'intrinsic' aspects, and modern notions of experimental economics provide the assessment criteria. However, this aspect of the history of economics held little interest for Pareto: to him, the history of economics is most potent and vibrant in the case of theories for which the sociological part of the economic phenomena influences the extrinsic aspect of theories, and vice-versa.

\section{History of Economics - the 'Sociological Part'}

When the extrinsic aspects of economic theories are significant, Pareto rejected the 'asymptotic' view of cumulative scientific knowledge. In particular, the asymptotic scientific progress does not apply to theories that treat the 'sociological part' of the economic phenomenon through deductive reasoning based on a hypothetical proposition. As the subjective intent of action pertaining to the sociological part of the economic phenomenon is not a constant force on human action in like objective circumstances, such an approach yields deductive rationalisation rather than experimental science.

The difference between theories with and without asymptotes can be well illustrated by considering Pareto's distinction between ophelimity and utility. Deductions concerning exchange and production are based on the notion of ophelimity - the relationship of convenience between a person and things - and behaviour that maximises ophelimity may be roughly confirmed experimentally. That is, stable equilibrium in exchange and production can be observed by monitoring price averages for consumer goods and productive serves and the fundamental theorems of welfare economics are consistent with this observed relationship. However, when deductions are based on propositions about utility, which extends the notion of ophelimity to include benefits from relationships between a person and other people (including third parties), hypothetical deductions are unlikely to be confirmed by experimental observation. When economic theories are deduced from a hypothetical postulate based on utility and concerning 'things' other people should 
have, or how other people should behave, they have little intrinsic (scientific) merit because they are generally not confirmed by experimental observation. Nevertheless, their extrinsic elements are numerous and Pareto was a strong advocate of economists undertaking historical studies of non-experimental economic theories over history to identify regularities of the range of subjective influences on the economic phenomenon that are not amenable to theory based on axiomatic representation.

\section{History of Economics as Experimental Economics}

In general terms, Pareto treated action as falling within the 'sociological part' of economic phenomena when individuals, or groups of individuals, act to directly or indirectly redistribute economic goods. While theories which advocate some redistribution of economic goods are phrased in terms of collective benefits, benefits for certain classes of disadvantaged people etc, he interpreted the outcome in terms of the relative change in access to productive resources by speculators (high risk investors and workers whose pecuniary interests depend on high risk economic activity) and rentiers (low risk investors, savers and workers in secure employment whose pecuniary interests do not directly depend on the activity of speculators). This is especially the case for the activities of government: trade/protection policy, fiscal policy and monetary policy all have distributive consequences that alter resources available to speculators of rentiers. Private actions may also be influenced by dynamic factors that relate to changes in sentiment: changes in economic and social equilibria may alter the distribution of economic goods and impact on economic growth. It is the history of economic theories pertaining to such phenomena that most interested Pareto, as they provided fertile ground for developing theories of economic phenomena influenced by government decisions (and the influence of economic actions on government decisions).

The primary observed regularity that Pareto discerned from studying the history of economics is that theories on the economic role of government not only advocate change in the distribution of economic goods, it is overwhelmingly done in a manner that supports the interests of the governing classes and their supporters (prevailing political and economic elites united through informal patron-client relations) and to the disadvantage of potential alternative governing classes and the subject classes generally. For trade theory, fiscal theory or monetary theory; the story is essentially the same. Pareto illustrates the situation for monetary theories in "Economia Sperimentale".

"The theory of money is one of those that does not have asymptotes; it fluctuates indefinitely between the theory of money-as-a-token and moneyas-a-good; all that varies are the justifications that are offered for it and the methods through which it is forced on the public." (Pareto [1918] 1980, p. 734)

In short, Pareto used the history of economics to identify an enduring long period cyclical pattern, with theories fluctuating between stable currency (money-asa-good) theories and fiat money (money-as-a-token) theories, with the latter rationalising large increases in monetary emissions in particular circumstances. While the importance of a stable currency is usually acknowledged, fiat money theories advocating a policy of issuing of paper money in a manner that depreciates 
the value of a currency emerge at relatively irregular intervals, each time explaining why issuing money is beneficial in the current circumstance.

The specific purpose of Pareto's analysis of the history of economics is to investigate whether economic theories pertaining to the welfare of society reflect the interests of the prevailing government and related economic elites (e.g. speculators) against alternative elites (e.g. rentiers and competing political elites) and the subject classes generally. From the history of economics, Pareto's general answer is in the affirmative. He then seeks to verify this experimentally through the study of economic history. Staying with the example of monetary theory, Pareto found that stable monetary theories and policies dominate in the short period, but in the long term, the fluctuation between stable theories/policies and policies that deflate the value of currency is the principle regularity. Towards the end of World War I he wrote that:

"we are seeing measures being resuscitated that we thought were dead and buried forever, that they want us to believe that the future will resemble neither the past nor the present, that we will have no further reductions in the value of the unit of currency, in debts, in the various commitments of the States, that what has always been will never happen again, that the uniformity that was observed for so many centuries will disappear." (Pareto [1918] 1980, p. 736)

The relevance of this to current theory is direct. The history of monetary theory, and the practice of monetary policy, are both motivated by the prevailing and/or opposing economic and political elites who are attempting to defend, or acquire, economic benefits that derive from positions of political and economic authority. The success, and lack of such success, of public policies contribute to economic, social and political cycles, which Pareto links to the circulation of the elite.

"If one considers short periods of time, no longer than one century, one can suppose, at least for certain, indeed few countries, without moving too far way from experience, that money is an exclusively economic tool, and one can more or less accept the theory of money-as-a-good. However, for long periods of time, of several centuries, the sociological character of money becomes predominant, it appears as a tool that is always used to reduce the debts of the State and of certain social classes, and therefore as a potent factor in the circulation of those selected classes." (Pareto [1918] 1980, p. 736)

In an analogous way, Pareto considered the impact on the struggle between speculators and rentiers of policies advocates in theories of protection, public debt, taxation and 'public needs', all theories where the sociological part of the economic phenomenon dominates the economic part. The fiscal sociology that developed in Italy in the early twentieth century was largely inspired by Pareto, with important studies by Borgatta (1920) and Sensini ([1917] 1933). ${ }^{6}$ When theory was complemented by the study of economic history, Pareto confirmed his key regularity of the sociological part of the economic phenomenon: governments (and sometimes

\footnotetext{
${ }^{6}$ The contributions of Borgatta and Sensini and Italian fiscal sociology are considered in McLure (2004b, 2005).
} 
private entities) never leave private property unscathed. The methods that Pareto identified for non-voluntary redistribution of economic goods among speculators and rentiers include: (i) direct abolition of private debts (law);(ii) direct State bankruptcy (fiscal and monetary policy); (iii) changes in the value of currencies (monetary policy); (iv) reduction of public debt (through loose monetary policy); (v) state appropriation (fiscal policy); (vi) redistribution of goods from rich to the poor (fiscal policy); and (vii) price increases through protection and public or private monopolies (international and domestic trade policy). ${ }^{7}$

As an experimentalist, Pareto quite simply insisted that the abovementioned methods for redistributing economic goods be treated as regularities that must be reflected in logico-experimental theories of the sociological part of the economic phenomenon. He was dismissive and scathing when this was ignored and replaced by deduction from a hypothetical postulate. ${ }^{8}$

\section{4) Implications and Assessment}

Pareto's approach to the history of economics has implications for the character of textual analysis and for the type of intellectual historians who should undertake research in the history of economics. In regard to the first point, the modern benchmark that historians of economics use for textual analysis derives from "Textual Exegeses as a Scientific Problem" by George Stigler (1965). Given the objectives of this study, there are similarities and difference between the textual exegesis of Stigler and Pareto that warrant consideration. In regard to the second point, the question arises as to whether Pareto's approach to the history of economics is best undertaken by economists (because it investigates theories of the economic phenomenon) or sociologists (because it investigates theories pertaining to the sociological part of the economic phenomenon).

\section{Textual Exegesis}

Stigler's critical point is that relying on citations as evidence to support a particular interpretation of a scholar's work is generally misleading. Authors in history are often careless writers, or they may have had scatterings of theoretical elements that are not integrated. He regarded these diverse and unintegrated elements to be of little importance, and considered constant resort to citations as leading to different historians developing different interpretations of theory, some of which devalue the main conclusions of historical works. To correct this, Stigler advocated the principle of scientific exegesis, where the relative importance of particular aspects of a past economic theory is tested with reference to the original theorists' main conclusions.

"This rule of interpretation is designed to maximize the value of a theory to the science. The man's central theoretical position is isolated and stated in a strong form capable of contradictions by facts. The net scientific

\footnotetext{
${ }^{7}$ These methods are discussed in Pareto ([1918] 1980, pp, 737-741).

${ }^{8}$ In a 2 September 1917 letter to Benvenuto Griziotti, Pareto wrote that: "... the "science" of public finances knows little of economic equilibrium and nothing of social equilibrium; therefore in place of an understanding of real effects it substitutes a presumption of imaginary effects. I cannot concede that the economic state and the social state are not variously modified by various changes in the use of economic goods" (Pareto 1975: 984).
} 
contribution, if any, of a man's work is thus identified, amended if necessary, and rendered capable of evaluation and possible acceptance." (Stigler 1965, p.448).

Stigler also contrasts scientific exegesis against personal exegesis, which deals with what the author meant. Interpretation based on personal exegesis may be the same as that based on scientific exegesis, in such cases the theorist is working on positive theory, or they may be different, such as in cases where the theorist is not working on positive theory but still manages to contribute to the progress of science.

Stigler's approach has been criticised for assuming that the interpreter has prior knowledge of the work that is being reviewed. Emmett (2003, p527) notes that a hermeneutic circle emerges: to interpret an author's contribution to science, the intellectual historian must first know the author's central theoretical position. Moreover, the circle is only closed when considered in a timeless sense, with Stigler regarding the author's central scientific message as the received view of the economics profession. The outcome is a tendency to Whig history.

Pareto's goal for the history of economics only agrees with Stigler in respect to economic theories for which knowledge is asymptotic. That is, for the class of theories where the extrinsic element diminishes over time and the intrinsic element becomes more profound. For such theories, the Paretian approach too has a tendency to Whig theory, with the associated reliance on rational and experimental assessment criteria. The only notable difference between the two approaches to exegesis and theories with asymptotes is emphasis: Pareto placed much less emphasis on individual theorists' contributions to economics than Stigler, preferring instead to emphasise the general history of theories.

However, the critical difference between the two is that Stigler's scientific exegesis filters out and excludes the 'extrinsic' elements of theory. To Pareto, this is totally untenable, as he regarded the extrinsic elements of theory as the part for which textual analysis was most important. Scientific textual analysis of uniformities in the extrinsic aspect of theory provides insight into how interaction between sentiment and reason combine in theories, which is mirrored in actions. The text that is screened out in Stigler's scientific exegesis is precisely the text that Pareto treated as the most fertile field for the history of economics.

\section{Who should undertake Histories of Economic Thought}

Given Pareto's objective of using the history of economics to better understand the sociological part of the economic phenomenon, the question arises as to who should research, and review, studies in the history of economics: economists or sociologists? A similar issue has been discussed relatively recently, with Margaret Schabas (1992) indicating that the history of economics will, and should, be a subject for historians of science to shift research away from economists narrower focus on economic ideas and move towards a broader historical focus on the philosophy of science.

Prima facie, one may expect Schabas's assessment to be consistent with Pareto's view. He emphasised the theory of theories (sociology of knowledge) in studying the history of economics. He also examined the history of economics in 
conjunction with economic history, which complements Schabas's goal of exploring the conditions in which theories arise. Perhaps surprisingly then Pareto considered it "rather ridiculous that the history of economics is compiled mostly by people who do not know the science of Economics" (Pareto [1918] 1980, p.734).

Pareto's position on this issue is governed by two main factors: a concern about the capacity of non-economists to undertake research in the history of economics; and his emphasis on the experimental objective.

In regard to the first factor, the initial and critical analytical step is the differentiation of the intrinsic and extrinsic aspects of theory. This is a task that Pareto only entrusts to experimental economists, as the criteria for judging intrinsic merit is given by the current state of experimental economics. This implies that economists undertaking intellectual histories must also have knowledge of the "theory of theories" to analyse the extrinsic dimension and to then isolate the related general uniformities. The implication of this is that Pareto was wary of non-economists' ability to acquire a sound knowledge of experimental economics, with the associated risk that they may treat the intrinsic aspects of experimental economics as if they were extrinsic.

In regard to the second factor, Pareto regarded the history of economics as a means to a non-historical end: developing modern theories of the sociological part of the economic phenomenon. As a consequence, the investigative questions asked of historical texts derive primarily from non-historical concerns. The scholar to benefit most from such investigation is not the sociologist, or the intellectual historian, but the economist developing theory on the effect of government on the economic phenomenon. This position is not only in stark contrast to Schabas, but also to the general body of modern academic historians of economic thought.

\section{Intellectual Historical?}

Given Pareto's non-historical objective for studies in the history of economics and studies in economic history, it is useful to consider whether his approach to exegesis and the history of economics is really historical.

Texts examined under Pareto's approach are historical bodies of work. At this level, the approach he advocated is clearly historical. However, as the textual analysis is undertaken solely in terms of the relationship between logic and experimental observation, not all historians of economics would accept this as historical scholarship. For instance, comments by Peter Gronewegen (2002) and Luigino Bruni (2003) suggest that they may not class historical research that relies on the logic of theory (judged by modern standards of economic theory) as history of economics. Bruni points to dangers of 'modern exegesis' because consideration is not given to personal and social influences such as the prevailing culture of science, the author's life, the effect of the author's interlocutors or the effect of the author's sources. In Pareto's approach, none of these four elements appear as primary considerations. It is the relationship between fact and theory that is decisive, with emphasis given to the rise and fall of theories that are dominated by extrinsic elements outweighing concerns about the contribution of any particular author. 
In addition, the level of generalisation associated with Pareto's approach is much greater than that usually pursued by intellectual historians. For example, in the case of monetary theory, his approach is primarily directed towards establishing whether theories support stable or inflationary monetary policies, with the theoretical form of such theories treated as a secondary issue to the policy being advocated. The theoretical form is largely treated as a mechanism to rationalise an outcome, with the interests and sentiments served by such outcomes being the prime interest. In mainstream history of economics, the emphasis is typically reversed: the essential characteristics of a theory, its development, reception and legacy are all issues of primary importance. For example, a purely Paretian history of twentieth century monetary theory would be more concerned with the policies advocated by Keynesian, monetarist or new-classical theories (i.e. stable monetary policies or inflationary policies) than the formal representation of the theories developed by these schools.

Nevertheless, when Pareto's approach is considered with respect to the criteria that Ian Kerr (2002) associated with the "Value of the History of Economic Thought", the value of the history of economics generally, and that of Pareto's approach to the field specifically, overlap significantly. Kerr suggests that that the history of economic thought is of value for: its intrinsic worth ${ }^{9}$ (a pure consumption activity); enriching understanding of the discipline (demonstrating the development of ideas); avoiding errors of the past (avoiding sunk costs); extending the range of hypothesis (while methods of analysis from the past may be redundant, the types of questions asked may still be relevant); highlighting unfulfilled evolutionary potential (issues lost in the subsequent syntheses my still be relevant - so the study of the work of the masters can have benefits); offsetting neglected holism (relevance of integrated systems), preserving alternative paradigms (preserve intellectual heritage, as we attempt to preserve cultural heritage); and providing long term perspective (transcending fads and fashion).

Pareto's approach to the history of economics meets several of these criteria. It is intended to enrich understanding of the discipline, avoid errors of the past, extend the range of hypothesis, consider unfulfilled evolutionary potential and provide a long term perspective on the development of theories. While preservation of alternative paradigms is not a specific objective of the Paretian approach, it is an indirect consequence of treating theories of the past as the factual data for textual analysis. However, Pareto placed little or no emphasis on the history of economics as mechanism for satisfying human curiosity or reducing the neglect of holism (although, he did not deny the intrinsic scientific merit of holism, in either the history of theory or contemporary theory, as long as holistic theories were also experimental).

Nevertheless, it must be conceded that the non-historical objectives of Pareto's history of economics has the effect of directing attention away from matters that modern intellectual scholars regard as fundamental. This raises the question, can Pareto's approach to textual analysis be utilised in modern histories of economic thought undertaken without regard to the development of contemporary theories? I believe that it can: the fundamental distinction between the economic and the sociological parts of theory of the economic phenomenon with textual exegesis based on the intrinsic and the extrinsic aspects of theory, and the associated identification of

\footnotetext{
${ }^{9}$ Kerr uses the term intrinsic in relation to the satisfaction of intellectual curiosity, and not the experimental significance of theory (as used by Pareto).
} 
the asymptotic and non-asymptotic aspects of theory, provide the basis for a historical framework that first isolates rational, sentimental and experimental elements of theory and then permits concurrent development of Whig history and the sociology of scientific knowledge. Of course, there can be no suggestion that Paretian textual analysis should replace modern historiography - constructivism, the new sociology of scientific knowledge and other approaches retain their value for the history of economic thought. However, it complements modern research methods and provides a basis for uniting apparently contradictory methods in the history of economic thought, with rational and sociological constructions becoming complements.

\section{5) Conclusion}

Pareto's approach to the history of economics has been neglected by historians of economics. Although 'neglect' is a very strong term, in this case it is appropriate because Pareto's views on the history of economics are an important feature of the history of experimental economics. Intellectual historians should consider Pareto's views on the history of economics for the same reasons that they have considered his choice theory: they are both important aspects of the same issue - the development of an experimental approach to economic theory. The subject is also relevant to historical studies of historiography, although for a negative reason: to consider why Pareto's approach to the history of economics did not prove influential. Scholars interested in contemporary historiography would also benefit from considering Pareto's approach to textual exegesis (especially the distinction between intrinsic/asymptotic the extrinsic/non-asymptotic aspects of theories pertaining to the 'economic' and the 'sociological' parts of the economic phenomenon) because it may complement modern research methods in the history of economics.

Finally, the role that Pareto assigned to the history of economics should not be dismissed. The sociological aspect of the economic phenomenon continues to prove resistant to realistic Cartesian modelling, and in such circumstances, the history of economics may still provide a useful mechanism for developing experimental theory.

\section{References}

Borgatta, G. (1920) "Lo Studio Scientifico dei Fenomeni Finanziari”, Giornale degli Economisti e Rivista di Statistica, 31(60), pp. 1- 24 and 81-116.

Luigino Bruni (2003) "Michael McLure, Pareto Economics and Sociology [sic]: The Mechanical Analogy", Journal of the History of Economic Thought, 25(1), pp113-115.

Clark, J. B. (1907) Essentials of Economic Theory, Macmillan, New York.

Emmet, R. B. (2003) "Exegesis, Hermeneutics, and Interpretation", in Warren Samuels, Jeff E. Biddle, and John B. Davis (eds) $A$ Companion to the History of Economic Thought, Blackwell Publishing, Maldon and Oxford, pp523-537.

Finer, S.E (ed) (1966) Vilfredo Pareto: Sociological Writings, translated by Derick Mirfin, Pall Mall Press, London 
Gronewegen, Peter (2002) "Michael McLure, Pareto Economics and Society: The

Mechanical Analogy", History of Economics Review, 35, Winter, pp147-149.

Kerr, I. (2002) "The Value of the History and Economic Thought", Journal of Economic and Social Policy, 6(2), Winter, 2002, pp88-99.

Leroy-Beaulieu, P. (1896), Traité théorique et pratique d'Economie politique, Tome III, Librairie Guillaumin Paris.

Marchionatti, R. and E. Gambino (1997) "Pareto and Political Economy as a Science: Methodological Revolution and Analytical Advances in Economic Theory in the 1890s", Journal of Political Economy, vol.105, no.61, pp1322-1347.

Marchionatti, R. (1999) "The Methodological Foundations of Pure and Applied Economics. An Anti-Walrasian Program", Revue Européenne des Sciences Sociales, vol. 37, no. 16, pp277-294.

McLure, M (1999) "Pareto on the Cause of Value: Maurice Dobb's Partial Assessment", History of Economics Review, vol.30, Summer, pp56-67.

McLure, M. (2004a) "Interpreting the History of Economics", Review Essay, History of Economics Review, No.39, pp. 88-96.

McLure, M. (2004b) "La Sociologia Finanziaria di Gino Borgatta", Pensiero Economico Italiano, 12(2), Atti dei Convegni: La scuola di economia di Torino: da Cognetti de Martiis a Einaudi, pp. 191-203.

McLure, M. (2005) "Italian Fiscal Sociology: a Reflection of the Pareto-Griziotti and Pareto-Sensini Letters on Fiscal Theory", European Journal of the History of Economic Thought, 12(4).

Pareto, V. [1901-02] (1974) I Sistemi Socialisti [Les Systèmes Socialistes], Torino: Unione Tipografico-Editrice Torinese, Torino.

Pareto, V. [1916] (1935) Mind and Society [Trattato di Sociologia Generale], New York: Harcourt, Brace and Company.

Pareto, V. [1918] (1980) "Economia Sperimentale", Ouvres Complètes, Tome.XXII, Écrites sociologiques mineurs, ed. G. Busino, Librairie Droz, Genéve, pp. 719-743.

Pareto, V. (1975) “A Benvenuto Griziotti”, letter of 2 September 1917, in Giovanni Busino (ed) Correspondance, vol 19/2, Euvres Complètes, Genéve: Librairie Droz: 983-5.

Parsons, T. [1937] (1968) The Structure of Social Action, Vol 1, The Free Press, New York.

Perlman, M. (2003) "The History of Ideas and Economics", in Warren Samuels, Jeff E. Biddle, and John B. Davis (eds) A Companion to the History of Economic Thought, Blackwell Publishing, Maldon and Oxford, pp 634654.

de Pietri-Tonelli, A. and Bousquet, G. (1994) Vilfredo Pareto: Neoclassical Synthesis of Economics and Sociology Macmillan, Houndmills.

Sensini, G. [1917] (1933) "La Finanza Sociologica", Studi di Scienze Sociali, (1), Casa Libraria Editrice Italiana, Roma, pp. 232 - 252.

Supino C. (1904) Principi di economia politica, Luigi Pierro, Napoli.

Schabas, M. (1992) "Breaking Away: History of Economics as History of Science", History of Political Economy, 24(1), pp187-203 
Schumpeter, J. A. (1954) A History of Economic Analysis, Oxford University Press, New York

Stigler, G. (1965) “Textual Exegesis as a Scientific Problem”, Economica, Vol. 32., No 32, pp 447-450.

Tarascio, V. J. (1968) Pareto's Methodological Approach to Economics, University of North Carolina Press, Chapel Hill 